\title{
BMJ Open Longitudinal survey of condom use across a US Navy and Marine Corps shipboard deployment
}

\author{
Judith Harbertson, ${ }^{\oplus, 2}$ Kimberly De Vera, ${ }^{1,2}$ Paul T Scott, ${ }^{3}$ Yuanzhang Li, ${ }^{3}$ \\ Richard A Shaffer, ${ }^{2}$ Nelson L Michael, ${ }^{3}$ Braden R Hale ${ }^{4}$
}

To cite: Harbertson J, De Vera K, Scott PT, et al. Longitudinal survey of condom use across a US Navy and Marine Corps shipboard deployment. BMJ Open 2019;9:e028151. doi:10.1136/ bmjopen-2018-028151

- Prepublication history and additional material for this paper are available online. To view these files, please visit the journal online (http://dx.doi. org/10.1136/bmjopen-2018028151).

Received 26 November 2018

Revised 8 March 2019

Accepted 29 May 2019

Check for updates

(C) Author(s) (or their employer(s)) 2019. Re-use permitted under CC BY-NC. No commercial re-use. See rights and permissions. Published by BMJ.

${ }^{1}$ Leidos, Inc, San Diego, California, USA

2Department of Defence HIV/ AIDS Prevention Programme, Defence Health Agency, San Diego, California, USA

${ }^{3}$ US Military HIV Research

Program, Walter Reed Army Institute of Research, Silver Spring, Maryland, USA

${ }^{4}$ University of California San Diego School of Medicine,

Division of Infectious Diseases, Department of Medicine, La Jolla, California, USA

Correspondence to Dr. Judith Harbertson; judith.harbertson.ctr@mail.mil

\section{ABSTRACT}

Objectives Condoms are highly effective in preventing sexually transmitted infections (STIs) but implementation is often inconsistent with use rarely examined across travel transition periods. We examined the prevalence of condom use among ship-assigned US military personnel across an overseas deployment cycle and identified factors associated with condom non-use.

Methods Longitudinal survey data were collected from ship-assigned US Navy/Marine Corps personnel on 11 ships before (T1), during (T2) and after (T3) an overseas deployment. The anonymous, self-completed survey included demographics, condom use at last sex, STI diagnosis, alcohol misuse and drug use with sex. Descriptive and generalised regression model analyses were conducted.

Results Analysis included 1900 (T1), 549 (T2) and 1168 (T3) personnel who reported age, sex and condom use/ non-use at last sex. The proportion reporting condom use was significantly higher during T2 $(53 \%, p<0.0001)$ than T1 $(27 \%)$ or T3 $(28 \%)$, with STI prevalences of $1 \%$ (T1), $7 \%$ (T2) or $2 \%$ (T3), with fewer (29\%) sexually active individuals at T2. In adjusted models, condom non-use was associated with hazardous alcohol use (OR 1.44, $95 \% \mathrm{Cl} 1.21$ to 1.71), or drug use to enhance sex (OR 1.37, $95 \% \mathrm{Cl} 1.06$ to 1.77$)$, but transactional sex was negatively associated (OR $0.69,95 \% \mathrm{Cl} 0.50$ to 0.84 ).

Conclusions Condom use was highest during deployment, as was STI prevalence (among non-users), possibly reflecting concentration of high-risk sexual activities/individuals and/or sexual partners more likely to be infected. Higher condom use with transactional sex likely reflects awareness of higher STI risk. These data can be used to facilitate targeted interventions to reduce STI transmission and may extend to similarly aged cohorts travelling outside the US (eg, college students on spring break).

\section{INTRODUCTION}

Sexually transmitted infections (STIs), particularly Chlamydia trachomatis and Neisseria gonorrhoea, are the most commonly reported infectious diseases within Department of Defence and the USA. ${ }^{2}$ Condoms are a well-known and effective STI prevention method,,$^{3-5}$ but compliance varies by

\section{Strengths and limitations of this study}

- Despite access and logistical challenges administering surveys, this study successfully collected condom use data for the first time across a complete deployment cycle (before (T1), during (T2) and after (T3) deployment) among ship-assigned US Navy and Marine Corps personnel with a large final sample size: 1900 (T1), 549 (T2) and 1168 (T3).

- Prevalence of not using a condom at last sex was calculated for each time point and associated factors were examined using generalised regression model analyses.

- Data were collected on condom use at last sex which may not correlate with frequency or regular usage.

- Participants were not asked what type of sexual partner they used a condom with at last sex, use may vary by partner type and should be examined more closely in future analyses.

- Data were self-report and therefore subject to recall and desirability bias, the short time periods assessed and anonymity of the survey may have minimised the impact of this.

demographic characteristics and other correlates $^{6-8}$ including post-traumatic stress disorder (PTSD) and major depressive disorder (MDD). ${ }^{8}$ Condom use has not been examined across a deployment cycle (pre-deployment period, deployment, post-deployment period) among ship-assigned US military personnel and could inform STI risk during transition periods among military and civilian populations who travel.

This study examined condom use at last sexual encounter and associated factors among sexually active, ship-assigned activeduty US Navy and Marine Corps personnel within 12 months prior to deployment, during deployment and 2 to 3 months following deployment. Of particular interest was how condom use varied in association with risky sexual behaviour (eg, transactional sex), alcohol and drug consumption 
and psychological and emotional well-being (eg, PTSD, depression) at different time points.

\section{MATERIALS AND METHODS}

\section{Study design and population}

A self-reported, anonymous, voluntary survey gathered demographic, sexual behaviour, alcohol and drug use and other data during 2012 to 2014 among active-duty US Navy and Marine Corps personnel as part of a longitudinal study described elsewhere. ${ }^{9-11}$ Paper surveys were self-administered at three time periods to assess history and behaviours in a participant's lifetime and in the preceding 3 months or 12 months of deployment (T1), during deployment (T2) and since returning from deployment (ie, 2 to 3 months post deployment, T3). Personnel were recruited from 11 deploying US Navy Third Fleet ships via convenience sampling; all departments on the ship were recruited to maximise representation of all shipboard personnel. Data were collected from available participants on the same ship, with some participants completing two or all three time points, but most completing the survey at only one time point (T1, T2 or T3). All participants provided informed consent.

\section{Inclusion criteria}

Study participants were active-duty US Navy and Marine Corps personnel assigned to a participating US Third Fleet ship. To be included in analysis, participants had to report they were sexually active in the time period, age and gender. Participants were defined as sexually active if they indicated sexual activity in the time period by providing a yes or no response to the question 'The last time you had sex (during this deployment, T2 only), did you or your partner use a condom?' The T1 time period included only those who reported sex in the past 3 months.

\section{Measures}

The primary outcome was condom use at last sexual encounter. Participants were defined as using a condom at last sex if they reported 'Yes' to the question 'The last time you had sex (during this deployment, T2 only), did you or your partner use a condom?' Hazardous alcohol use, ${ }^{12}$ transactional sex, ${ }^{13}$ drug-enhanced $\operatorname{sex}^{14}{ }^{15}$ and positive screen for PTSD or $\mathrm{MDD}^{16}$ were key exposures examined in the analysis.

Hazardous alcohol use was measured using the Alcohol Use Identification Test - Consumption (AUDIT-C), an abbreviated version of the AUDIT. Hazardous alcohol use was defined as AUDIT-C scores of $\geq 3$ for women and $\geq 4$ for men, which have been validated as cut points for screening in both civilian and military populations. ${ }^{17-19}$ Transactional sex was defined as sex with a sex worker or giving or receiving sex for money, goods (eg, gifts, free drinks, drugs, housing, etc) or improved work conditions within the past 3 months prior to deployment (T1), during deployment (T2) or after deployment (T3). Drug-enhanced sex was defined as use of prescription or non-prescription drugs or substances (excluding lubricant), other than alcohol, to enhance the experience before sex, alone or in combination with another drug, within the 12 months prior to deployment, during or after. PTSD and MDD were assessed using the PTSD Checklist-Civilian Version (PCL-C) ${ }^{20}$ and Centre for Epidemiologic Studies Depression Scale (CESD), ${ }^{21}$ respectively. Consistent with criteria described in the Diagnostic and Statistical Manual of Mental Disorders, fourth edition, a PCL-C score of $\geq 50$ and endorsement of a moderate level of $\geq 1$ intrusion symptoms, $\geq 3$ avoidance symptoms and $\geq 2$ hyperarousal symptoms indicated a positive screen for PTSD. ${ }^{22} 23$ A positive screen for MDD was defined as a CES-D score of $\geq 22$.

Covariates included age, sex, race/ethnicity, marital status, level of education, sex of sexual partner(s), report of multiple sexual partners and self-reported diagnosis with an STI. Unless otherwise noted, sexual risk behaviour occurred within the previous 12 months (for the pre-deployment survey, T1), during the deployment time period (for the deployment survey, T2) and within the 2 to 3 months since returning from deployment (for the post-deployment survey, T3). Participants reported sex (male, female or both) of sexual partners. Participants were defined as having multiple sexual partners if they reported $\geq 2$ total sexual partners, or if they had a partner outside their main relationship. Participants were defined as having an STI diagnosis if they self-reported that a doctor or other health provider told them they had gonorrhoea, chlamydia, syphilis or trichomoniasis, or if they reported having a burning discharge from their penis (if male) in the past 3 months, during or after.

\section{Statistical analysis}

Descriptive analyses were conducted to describe condom use, main exposures (hazardous alcohol use, transactional sex, drug-enhanced sex, positive screen for PTSD or MDD) and covariates (demographic and other key characteristics) of the sample population across the deployment cycle. Factors known to be significantly associated with condom use and a set of main exposures were chosen from previous data analysis conducted in US and foreign militaries, and with civilians in the US, Britain and Amsterdam. ${ }^{12-16}$ Generalised linear regression models were constructed to determine effects of main exposures on condom use. For longitudinal data, generalised estimating equations were used to estimate parameters and significances. Main exposures were analysed for interaction with time to test whether effects on condom use were homogeneous across the deployment cycle. For significant interactions, models were stratified by time period. The Akaike information criterion and likelihood ratio test were used to remove unnecessary factors having only minor contributions to the model, with exception of basic demographic factors, such as gender, age and race. Missing records varied among the factors of interest, hence missing values were included as part of their own category for each factor, and the same data were used for 
all models during the model building process and in the final selected models. Results for these missing categories were not included in final tables. Data were analysed using SAS software V.9.3 (SAS Institute, Inc, Cary, North Carolina), with statistical significance defined as $\mathrm{p}<0.05$ for all analyses.

\section{Patient and public involvement}

Formative data were collected among US military personnel to inform content and implementation of the questionnaire. The source population for the current study and formative research sample were the same. US military medical and operational leadership serving the current study population were consulted during study design development and are informed when study analyses are completed.

\section{RESULTS}

Of the 6669 surveys distributed for voluntary self-administration across the deployment cycle, 2593 of 2811 (92.2\%) of T1, 2070 of $2270(91.2 \%)$ of T2 and 1556 of $1588(98.0 \%)$ of T3 surveys were completed by participating personnel. Of those, after excluding those missing sex, age and condom use response, analysis included $81.7 \%$ ( $\mathrm{n}=1900$ of 2326 ) who were sexually active at $\mathrm{T} 1$, $29.2 \%(\mathrm{n}=549$ of 1877$)$ at T2 and $84.3 \%(\mathrm{n}=1168$ of 1386$)$ at T3 (see online supplementary figure 1 ).

Table 1 shows demographic and behaviour data by time point. The majority identified as male of white race/ ethnicity with a high school education, between the ages of 17 to 25 years old at each time point, although a larger proportion $(70.3 \%)$ of $\mathrm{T} 2$ respondents were 17 to 25 years and single than at T1 or T3. Approximately $16 \%$ of participants at $\mathrm{T} 1$ were senior enlisted or officer ranking (see online supplementary table 1 ). The number of individuals reporting sexual activity was significantly less in $\mathrm{T} 2$ $(p<0.001)$ compared with other time points.

Unadjusted proportions of condom use by demographics, sexual risk behaviour, alcohol and drug use and mental health are shown in online supplementary table 1. Among unmarried female personnel, condom use at last sex was 29\% (T1), 30\% (T2) and 26\% (T3), but among unmarried male personnel was $42 \%$ (T1), 66\% (T2) and $45 \%$ (T3).

The overall STI prevalence was $2.3 \%$, with the highest proportion reported during T2 as shown in table 1 and figure 1. Males accounted for $88.8 \%(n=71 / 80)$ of the reported STI diagnoses. Condom use was significantly $(\mathrm{p}<0.0001)$ higher during T2 $(52.6 \%, \mathrm{n}=289 / 549)$ than T1 $(26.6 \%, \mathrm{n}=506 / 1900)$ and T3 $(27.7 \%, \mathrm{n}=324 / 1168)$ (see figure 1).

A significantly higher proportion of STIs $(\mathrm{p}<0.001)$ were reported among individuals not using a condom at last sex at T2, than T1 or T3; STIs were reported eight times more often at T2 $(\mathrm{n}=25 / 260,9.6 \%)$ than $\mathrm{T} 1$ $(\mathrm{n}=16 / 1385,1.2 \%)$ and five times more often at T2 than T3 ( $\mathrm{n}=18 / 844,2.1 \%)$ (see figure 2$)$. The proportion of individuals reporting using a condom at last sex increased at T2 (53\%) and returned to pre-deployment levels (T1, $27 \%)$ at T3 (28\%). STIs were reported among those who reported they used a condom at last sex at $\mathrm{T} 1(0.6 \%$, $\mathrm{n}=3 / 505)$, T2 $(3.8 \%, \mathrm{n}=11 / 288)$ and T3 $(2.2 \%, \mathrm{n}=7 / 324)$.

Further stratification showed that individuals who reported both same and opposite sex partners had the highest proportions of STIs at T2 among both those who used a condom $(n=4 / 7)$ and did not use a condom $(\mathrm{n}=10 / 14)$ at last sex, compared with those reporting same sex partners only ( $\mathrm{n}=3 / 24$ non-use, $\mathrm{n}=0 / 7$ use) or only opposite sex partners $(n=3 / 24$ non-use, $n=7 / 265$ use) but the numbers were small.

A significantly higher proportion of personnel reporting only same-sex or same-sex and opposite-sex sexual partners reported drug-enhanced sex than personnel reporting only opposite-sex partners at T2 and T3 (T2: $34.8 \%(\mathrm{n}=16$ of 46$)$ vs $7.9 \%(\mathrm{n}=32$ of 401$)$; T3: $30.9 \%$ ( $n=17$ of 55 ) vs $12.8 \%$ ( $n=118$ of 804$)$, respectively).

Because the associations between condom non-use and main exposures did not significantly differ by time point, the multivariable model was not stratified by time point (table 2). In the final adjusted multivariable model, the odds of not using a condom at last sex were significantly higher among participants who were 35 years of age or older (OR 2.28, 95\% CI 1.55 to 3.37), female (OR 1.93, 95\% CI 1.55 to 2.40 ) and married (OR 5.76, 95\% CI 4.54 to 7.31) and significantly lower among those reporting multiple sexual partners (OR $0.69,95 \%$ CI 0.57 to 0.83 ). The odds of not using a condom at last sex were also significantly higher among those screening positive for hazardous alcohol use (OR 1.44, 95\% CI 1.21 to 1.71 ) and using drugs to enhance sex (OR 1.37, 95\% CI 1.06 to 1.77 ), but significantly lower for those who engaged in transactional sex (OR 0.69, 95\% CI 0.50 to 0.94 ). A positive screen for PTSD or MDD was not significantly associated with not using a condom at last sex.

\section{DISCUSSION}

Changes in condom use observed among US Navy and Marine Corps personnel during the deployment time period may inform risk mitigation strategies in militaries and can be extended to similar age cohorts during holiday travel (eg, college spring break), and also to other young, single civilians travelling outside the USA with the opportunity to engage in casual sex. This is the first study to date to report on condom use across a shipbased deployment cycle. When stratified by time period, the proportion of condom use at last sex was significantly higher during deployment $(52.6 \%)$ compared with pre-deployment (26.6\%) and post-deployment (27.7\%). Despite this increase in condom use during deployment, STI prevalence was also highest during deployment, however, only $29 \%$ of personnel at T2 were sexually active (compared with T1: 82\% and T3: 84\%). However, over half of all STIs were reported in the pre-deployment and post-deployment time periods, suggesting that a higher 
Open access

Table 1 Characteristics of sexually active US Navy and Marine Corps personnel $(n=3617)$

\begin{tabular}{|c|c|c|c|}
\hline & T1 $(n=1900)$ & T2 $(n=549)$ & T3 $(n=1168)$ \\
\hline Characteristic & n (\%) & n (\%) & n (\%) \\
\hline \multicolumn{4}{|l|}{ Age, years } \\
\hline $17-20$ & $228(12.0)$ & $92(16.8)$ & $81(6.9)$ \\
\hline $21-25$ & $871(45.8)$ & $294(53.6)$ & $514(44.0)$ \\
\hline $26-34$ & $537(28.3)$ & $127(23.1)$ & $402(34.4)$ \\
\hline $35+$ & $264(13.9)$ & $36(6.6)$ & $171(14.6)$ \\
\hline \multicolumn{4}{|l|}{ Gender } \\
\hline Male & $1493(78.6)$ & $386(70.3)$ & $885(75.8)$ \\
\hline Female & $407(21.4)$ & $163(29.7)$ & $283(24.2)$ \\
\hline \multicolumn{4}{|l|}{ Race/ethnicity } \\
\hline White & $1022(54.5)$ & $293(54.9)$ & $591(51.5)$ \\
\hline Black or African American & $226(12.0)$ & $76(14.2)$ & $194(16.9)$ \\
\hline Spanish/Hispanic/Latino & $281(15.0)$ & $53(9.9)$ & $145(12.6)$ \\
\hline Other & $348(18.5)$ & $112(21.0)$ & $218(19.0)$ \\
\hline \multicolumn{4}{|l|}{ Education level completed } \\
\hline$\leq$ High school, GED & $778(41.3)$ & $244(44.9)$ & $395(34.0)$ \\
\hline $\begin{array}{l}\text { Some college, vocational } \\
\text { (non-military) }\end{array}$ & $817(43.4)$ & $242(44.5)$ & $562(48.4)$ \\
\hline$\geq$ Undergraduate degree & $288(15.3)$ & $58(10.7)$ & $204(17.6)$ \\
\hline \multicolumn{4}{|l|}{ Marital status } \\
\hline Single, uncommitted & $533(28.1)$ & $252(46.0)$ & $316(27.2)$ \\
\hline $\begin{array}{l}\text { Single, committed } \\
\text { relationship }\end{array}$ & $415(21.9)$ & $142(25.9)$ & $284(24.4)$ \\
\hline Married & $823(43.3)$ & $86(15.7)$ & $493(42.4)$ \\
\hline $\begin{array}{l}\text { Divorced, separated or } \\
\text { widowed }\end{array}$ & $128(6.7)$ & $68(12.4)$ & $69(5.9)$ \\
\hline \multicolumn{4}{|l|}{ Sex of sexual partner(s) ${ }^{\star}$} \\
\hline Opposite sex partners only & $1618(92.7)$ & $470(90.0)$ & $1033(94.3)$ \\
\hline Same sex partners only & $71(4.1)$ & $31(5.9)$ & $45(4.1)$ \\
\hline $\begin{array}{l}\text { Both opposite sex and same } \\
\text { sex partners }\end{array}$ & $56(3.2)$ & $21(4.0)$ & $17(1.6)$ \\
\hline \multicolumn{4}{|l|}{ Number of sexual partners } \\
\hline$\geq 2$ sexual partners $\dagger$ & $785(42.0)$ & $344(63.0)$ & $411(35.4)$ \\
\hline$\leq 1$ sexual partner & $1083(58.0)$ & $202(37.0)$ & $749(64.6)$ \\
\hline \multicolumn{4}{|l|}{ Sexually transmitted infectionł } \\
\hline Yes & $19(1.0)$ & $36(6.6)$ & $25(2.1)$ \\
\hline No & $1871(99.0)$ & $512(93.4)$ & $1143(97.9)$ \\
\hline \multicolumn{4}{|l|}{ Transactional sex§ } \\
\hline Yes & $75(4.1)$ & $155(36.1)$ & $51(4.5$ \\
\hline No & $1753(95.9)$ & $275(64.0)$ & $1084(95.5)$ \\
\hline \multicolumn{4}{|l|}{ Drug-enhanced sexף } \\
\hline Yes & $338(19.7)$ & $51(10.9)$ & $139(13.4)$ \\
\hline No & $1376(80.3)$ & 417 (89.1) & $898(86.6)$ \\
\hline \multicolumn{4}{|l|}{ Hazardous alcohol use ${ }^{\star *}$} \\
\hline Yes & $1022(54.5)$ & $365(67.8)$ & $625(54.9)$ \\
\hline No & 855 (45.6) & $173(32.2)$ & $514(45.1)$ \\
\hline
\end{tabular}

Continued 
Table 1 Continued

\begin{tabular}{|c|c|c|c|}
\hline & T1 $(n=1900)$ & T2 $(n=549)$ & T3 $(n=1168)$ \\
\hline Characteristic & n (\%) & n (\%) & $\mathrm{n}(\%)$ \\
\hline \multicolumn{4}{|c|}{ Mental health screening††, 㧊 } \\
\hline No PTSD, no MDD & $1241(65.3)$ & $286(52.1)$ & $711(60.9)$ \\
\hline Unknown & $276(14.5)$ & $72(13.1)$ & 202 (17.3) \\
\hline
\end{tabular}

GED, General Equivalency Diploma; MDD, major depressive disorder; PTSD, post-traumatic stress disorder; T1, 3 to 12 months preceding deployment; T2, during deployment; T3, since returning from deployment.

*Includes lifetime sexual partners (T1), partners during T2, T3.

†Reported more than one sexual partner or partner outside main relationship in the past 12 months (T1), during T2, T3.

łIncludes Neisseria gonorrhoea , Chlamydia trachomatis, Trichomonas vaginalis or syphilis, or discharge (if male) in the past 3 months (T1), during T2, T3.

§Had sex with a sex worker, or gave/received sex for money, goods or improved work conditions in the past 3 months (T1), during T2, T3. qUsed prescription/non-prescription drugs or substances other than alcohol to enhance sex, or used Viagra, Viagra in combination with other drugs or poppers before or during sex in the past 12 months (T1), during T2, T3.

**Positive screen for hazardous alcohol use defined as Alcohol Use Identification Test - Consumption score of $\geq 3$ for women, $\geq 4$ for men. ††Positive screen for PTSD based on PTSD Checklist - Civilian Version score of $\geq 50$ and symptom criteria, past month (T1, T2, T3). ¥¥Positive screen for MDD based on a Centre for Epidemiologic Studies Depression Scale score of $\geq 22$, past week (T1, T2, T3).

number of STIs are acquired in the US; therefore STI prevention efforts focused exclusively during deployment port calls (or travel destinations for travelling civilians) would miss a majority of infections. In general, participants who remained sexually active during deployment had higher rates of risky behaviour (eg, multiple partners, transactional sex) and morbidity (eg, positive screen for hazardous use, MDD) and may resemble younger, single, sexually active, college age civilians who travel. The proportion of married individuals who remained sexually active at T2 dropped substantially (16\% vs $43 \%$ and $42 \%$ at $\mathrm{T} 1, \mathrm{~T} 3$ respectively), which may partially account for the increase in condom use and increased sexual risk

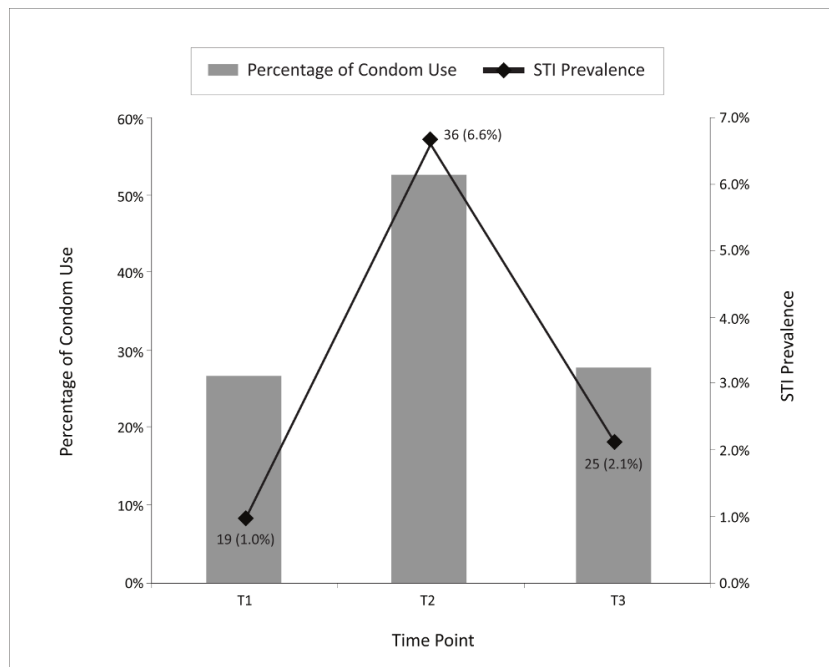

Figure 1 Percentage of participants who used a condom at last sex and STI prevalence among sexually active US Navy and Marine Corps personnel ( $n=3617)$. STI, sexually transmitted infections; T1, pre-deployment; T2, during deployment; T3, post-deployment. behaviour among the predominantly single personnel who remained sexually active during deployment.

Those engaging in transactional sex were more likely to use condoms at last sex, suggesting that individuals are aware of higher STI acquisition risk and are using condoms to protect themselves. A recent study conducted in Indiana among women arrested on prostitution charges and their social contacts, recorded type of partner (ie, romantic vs non-romantic) and feelings of being in love, twice daily. Women were more likely to use condoms with non-romantic partners on days when they reported any degree of falling in love, ${ }^{24}$ suggesting that feeling in love encourages condom use during transactional sex encounters with their non-romantic partner. Other USA based data among a broad sample of men and women

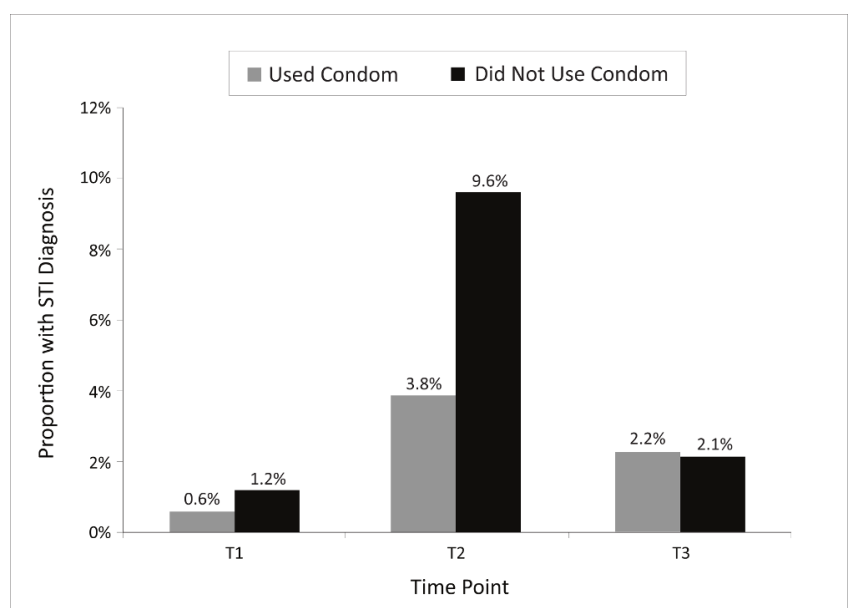

Figure 2 The proportion of sexually active US Navy and Marine Corps personnel reporting STI diagnosis at each time point among those who did not or did use a condom at last sex $(n=3617)$. STI, sexually transmitted infections; T1, predeployment; T2, during deployment; T3, post-deployment. 
Table 2 Adjusted odds* of not using a condom among sexually active US Navy and Marine Corps personnel $(\mathrm{n}=3617)$

\begin{tabular}{lll}
\hline Characteristic & AOR & $\mathbf{9 5 \%} \mathbf{C l}$ \\
\hline $\begin{array}{l}\text { Transactional sex } \dagger \\
\text { Yes }\end{array}$ & 0.69 & 0.50 to 0.94 \\
No & 1.0 & \\
Drug-enhanced sex $\ddagger$ & & \\
$\quad$ Yes & 1.37 & 1.06 to 1.77 \\
No & 1.0 & \\
Hazardous alcohol use§ & & \\
$\quad$ Yes & 1.44 & 1.21 to 1.71 \\
No & 1.0 & \\
Mental health screening ${ }^{* *}$ & & \\
$\quad$ PTSD or MDD & 1.13 & 0.93 to 1.38 \\
\hline No PTSD, no MDD & 1.0 & \\
\hline Unknown & 1.25 & \\
\hline
\end{tabular}

*Adjusted for age, sex, race/ethnicity, marital status, level of education, sex of sexual partner(s) and report of multiple partners. †Had sex with a sex worker, or gave/received sex for money, goods or improved work conditions in the past 3 months (T1), during T2, T3.

fUsed prescription/non-prescription drugs or substances other than alcohol to enhance sex, or used Viagra, Viagra in combination with other drugs or poppers before or during sex in the past 12 months (T1), during T2, T3.

§Positive screen for hazardous alcohol use defined as Alcohol Use Identification Test - Consumption score of $\geq 3$ for women, $\geq 4$ for men.

ПPositive screen for PTSD based on PTSD Checklist - Civilian Version score of $\geq 50$ and symptom criteria, past month (T1, T2, T3). **Positive screen for MDD based on a Centre for Epidemiologic Studies Depression Scale score of $\geq 22$, past week $(T 1, T 2, T 3)$. AOR, adjusted odds ratio; MDD, major depressive disorder; PTSD, post-traumatic stress disorder; T1, pre-deployment; T2, during deployment; T3, post-deployment.

visiting emergency departments showed lower rates of condom use among those engaging in transactional sex, but the study sample was predominantly female, older and had less education that the current study sample or the general civilian population which makes comparison difficult. $^{13}$

Prior studies among US men who have sex with men (MSM) reporting sildenafil use were significantly more likely to engage in unprotected anal sex compared with those not reporting sildenafil use, ${ }^{25}$ and MSM under the influence of drugs (eg, amphetamines, poppers, ecstasy) were significantly associated with having unprotected sex. ${ }^{26}$ In the current study, a higher proportion of personnel reporting same or same and opposite sex sexual partners also reported drug-enhanced sex, which may have accounted in large part for the significant association between drug-enhanced sex and not using a condom in adjusted analysis.
Prior studies examine condom use at a single time point, with estimates differing by sex and marital status. ${ }^{8} 2728$ Among unmarried service members, $32 \%$ of females of $43 \%$ of males (vs $26 \%$ to $30 \%$ of females and $42 \%$ to $66 \%$ of males in the current study) reported condom use at last sex across all service branches of the military. In the 2017 Youth Risk Behaviour Surveillance Study, a nationwide survey conducted among high school students in the USA, $47 \%$ of females and $61 \%$ of males reported condom use at last sex; whether these students are sexually active within committed or uncommitted relationships is not reported. Contrary to prior reports, the current study shows a remarkable increase in condom use during deployment, suggesting that only a subset of the population is having sex in non-US locations (younger, single) with condom use rates near equivalent to young, presumably single, high school students. The current study data suggest young age, single relationship status and deployment increase condom use among males; fairly unchanged condom use levels observed among females across the deployment cycle likely reflect prior data that show a lower proportion of women with casual partners, ${ }^{9}$ and is consistent with lower condom use reported among females in prior civilian studies. ${ }^{29}$

Although participants were recruited via convenience sampling, all departments on the ship were recruited to maximise representation of the US Navy and Marine Corps population. In addition, data were self-report and therefore subject to recall bias, but the short time periods assessed may have alleviated the issue. A proportion of participants responses to sensitive questions (substance use/alcohol) were missing or inaccurate, resulting in conservative estimates of these indicators. In addition, the condom use measure used was specific to the most recent sexual encounter and may not correlate with frequency or regular usage; however this measure has been used in several large national surveys (eg, Youth Risk Behaviour Surveillance Survey) and has found to be a reasonable measure for condom use over time.$^{30}$ Data were collected on condom use at last sex; condom use with a specific partner type was not analysed among those with more than one sexual partner.

This study provides the most current data on condom use within the US Navy and Marine Corps and is the first to examine usage across the deployment cycle (pre-deployment, post-deployment and during deployment). Although more STIs were reported during pre-deployment and post-deployment, STI prevalence was highest during deployment (when there were a smaller number of sexually active individuals), particularly among males; however, condom use at last sex almost doubled. Not using a condom during $\mathrm{T} 2$ appears to carry a much higher risk of STI acquisition than during T1 and T3, although the overall number of STIs was greater in T1 + T3 (ie, USA-based). Efforts to increase condom use and other STI prevention efforts should target young, single personnel and individuals who screened positive for alcohol misuse, or use of drugs to enhance sex during T2. STI prevention 
efforts at T1 and T3 should target demographic groups engaged in higher risk sexual activity. These trends are likely applicable to civilian populations such as college students or travellers abroad who may benefit from similar risk factor mitigation. Implementation of evidence-based behavioural interventions ${ }^{31}$ to increase condom use (1) among individuals or communities who engage in high risk behaviour (eg, multiple partners, drug use with sex, hazardous alcohol use, transactional sex), (2) during time periods when these individuals are planning to have sex in high STI prevalent locations and/or (3) with high STI prevalent populations may substantially reduce STI/ HIV acquisition/transmission risk. Development and implementation of effective clinical prediction tools are needed to screen/identify individuals meeting criteria for high STI acquisition risk so they can be included in interventions designed to increase condom use.

Contributors JH, BRH and PTS collaborated on study design, acquisition of data and interpretation of data. KDV, JH and $\mathrm{YL}$ drafted the manuscript. KDV, $\mathrm{YL}$ and $\mathrm{JH}$ conducted data analysis and interpretation of data. JH, BRH, PTS, YL, RAS, NLM provided critical revision of the manuscript.

Funding This work was supported by a cooperative agreement (W81XWH-07-20067) between the Henry M. Jackson Foundation for the Advancement of Military Medicine, Inc, and the US Department of Defence, under Work Unit No. 60546.

Disclaimer I am a military service member (or employee of the US Government). This work was prepared as part of my official duties. Title 17, USC, §105 provides the "Copyright protection under this title is not available for any work of the US Government." Title 17, USC, §101 defines a US Government work as work prepared by a military service member or employee of the US Government as part of that person's official duties. The views expressed in this article are those of the authors and do not necessarily reflect the official policy or position of the Department of the Navy, Department of the Army, Department of the Air Force, Department of Veterans Affairs, Department of Defense or the US Government. Approved for public release; distribution unlimited. This research has been conducted in compliance with all applicable federal regulations governing the protection of human subjects in research (NHRC.2010.0033).

Competing interests None declared.

Patient consent for publication Not required.

Ethics approval This study was approved by the Naval Health Research Centre Institutional Review Board (NHRC.2010.0033) and Walter Reed Army Institute of Research Human Subjects Protection Branch (WRAIR \#1766).

Provenance and peer review Not commissioned; externally peer reviewed.

Data sharing statement Additional analyses and publications are in development. Unpublished data are not available for distribution at this time.

Open access This is an open access article distributed in accordance with the Creative Commons Attribution Non Commercial (CC BY-NC 4.0) license, which permits others to distribute, remix, adapt, build upon this work non-commercially, and license their derivative works on different terms, provided the original work is properly cited, appropriate credit is given, any changes made indicated, and the use is non-commercial. See: http://creativecommons.org/licenses/by-nc/4.0/.

\section{REFERENCES}

1. Armed Forces Health Surveillance Center. Sexually transmitted infections, active component, U.S. armed forces, 2000-2012. MSMR 2013;20:7.

2. Adams DA, Thomas KR, Jajosky RA, et al. Summary of Notifiable Infectious Diseases and Conditions - United States, 2015. MMWR Morb Mortal Wkly Rep 2017;64:1-143.

3. Warner L, Stone KM, Macaluso M, et al. Condom use and risk of gonorrhea and Chlamydia: a systematic review of design and measurement factors assessed in epidemiologic studies. Sex Transm Dis 2006;33:36-51.
4. Holmes KK, Levine R, Weaver M. Effectiveness of condoms in preventing sexually transmitted infections. Bull World Health Organ 2004;82:454-61.

5. Workowski KA, Bolan GA. Centers for Disease Control and Prevention. Sexually transmitted diseases treatment guidelines, 2015. MMWR Recomm Rep 2015;64:1-137.

6. Reece M, Herbenick D, Schick V, et al. Condom use rates in a national probability sample of males and females ages 14 to 94 in the United States. J Sex Med 2010;7 Suppl 5:266-76.

7. Cachay E, Mar-Tang M, Mathews WC. Screening for potentially transmitting sexual risk behaviors, urethral sexually transmitted infection, and sildenafil use among males entering care for HIV infection. AIDS Patient Care STDS 2004;18:349-54.

8. Stahlman S, Javanbakht M, Cochran S, et al. Self-reported sexually transmitted infections and sexual risk behaviors in the U.S. Military: how sex influences risk. Sex Transm Dis 2014;41:359-64.

9. Harbertson J, Scott PT, Moore J, et al. Sexually transmitted infections and sexual behaviour of deploying shipboard US military personnel: a cross-sectional analysis. Sex Transm Infect 2015;91:581-8.

10. Harbertson J, Hale BR, Watkins EY, et al. Pre-deployment alcohol misuse among shipboard active-duty U.S. military personnel. Am J Prev Med 2016;51:185-94.

11. Harbertson J, Hale BR, Michael NL, et al. Missed opportunity to screen and diagnose PTSD and depression among deploying shipboard US military personnel. BJPsych Open 2016;2:314-7.

12. Tran BR, Thomas AG, Ditsela M, et al. Condom use behaviours and correlates of use in the Botswana Defence Force. Int J STD AIDS 2013;24:883-92.

13. Patton R, Blow FC, Bohnert AS, et al. Prevalence and correlates of transactional sex among an urban emergency department sample: Exploring substance use and HIV risk. Psychol Addict Behav 2014;28:625-30.

14. Mitchell KR, Prah P, Mercer CH, et al. Medicated sex in Britain: evidence from the third National Survey of Sexual Attitudes and Lifestyles. Sex Transm Infect 2016;92:32-8.

15. Heiligenberg M, Wermeling PR, van Rooijen MS, et al. Recreational drug use during sex and sexually transmitted infections among clients of a city sexually transmitted infections clinic in Amsterdam, the Netherlands. Sex Transm Dis 2012;39:518-27.

16. Marshall BD, Prescott MR, Liberzon I, et al. Posttraumatic stress disorder, depression, and HIV risk behavior among Ohio Army National Guard Soldiers. J Trauma Stress 2013;26:64-70.

17. Bradley KA, DeBenedetti AF, Volk RJ, et al. AUDIT-C as a brief screen for alcohol misuse in primary care. Alcohol Clin Exp Res 2007;31:1208-17.

18. Bush K, Kivlahan DR, McDonell MB, et al. The AUDIT alcohol consumption questions (AUDIT-C): an effective brief screening test for problem drinking. Ambulatory Care Quality Improvement Project (ACQUIP). Alcohol Use Disorders Identification Test. Arch Intern Med 1998;158:1789-95.

19. Department of Veterans Affairs and the Department of Defense. Substance use disorder pocket guide overview. 2011. Available at http://www.healthquality.va.gov/guidelines/MH/sud/SUDPocketGui deOverview.pdf (Accessed: Oct 2018).

20. Weathers FW, Litz BT, Herman DS, et al. Presented at: Ninth Annual Meeting of the International Society for Traumatic Stress Studies. San Antonio, TX, 1993.

21. Radloff LS. The CES-D Scale: A self-report depression scale for research in the general population. Appl Psychol Meas 1977;1:385-401.

22. Hoge CW, Castro CA, Messer SC, et al. Combat duty in Iraq and Afghanistan, mental health problems and barriers to care. US Army Med Dep J 2008:7-17.

23. Ruggiero KJ, Del Ben K, Scotti JR, et al. Psychometric properties of the PTSD checklist-civilian version. J Trauma Stress 2003;16:495-502.

24. Roth AM, Rosenberger JG, Hensel DJ, et al. The moderating role of love in the relatioiship between partner type and condom use among women engaging in paid vaginal sex. Sex Health 2016;13:170-6.

25. Swearingen SG, Klausner JD. Sildenafil use, sexual risk behavior, and risk for sexually transmitted diseases, including HIV infection. Am J Med 2005;118:571-7.

26. Celentano DD, Valleroy LA, Sifakis F, et al. Associations between substance use and sexual risk among very young men who have sex with men. Sex Transm Dis 2006;33:265-71.

27. Barlas FM, Higgins WB, Pflieger JC, et al. Department of Defense Health Related Behaviors Survey of Active Duty Military Personnel2013 March 2015. 2011. Available at http://www.murray.senate.gov/public/_cache/ files/889efd07-2475-40ee-b3b0-508947957a0f/final-2011-hrb-activeduty-survey-report.pdf (Accessed: Oct 2018). 
28. Kann L, McManus T, Harris WA, et al. Youth risk behavior surveillance - United States, 2017. MMWR. Surveillance Summaries 2018;67:1-114.

29. Svensson P, Sundbeck M, Persson KI, et al. A meta-analysis and systematic literature review of factors associated with sexual risk-taking during international travel. Travel Med Infect Dis 2018;24:65-88.
30. Younge SN, Salazar LF, Crosby RF, et al. Condom use at last sex as a proxy for other measures of condom use: is it good enough? Adolescence 2008;43:927-31.

31. Scott-Sheldon LA, Huedo-Medina TB, Warren MR, et al. Efficacy of behavioral interventions to increase condom use and reduce sexually transmitted infections: a meta-analysis, 1991 to 2010. J Acquir Immune Defic Syndr 2011;58:489-98. 